\title{
Comparison of ocular hypotensive effects of 3 dosages of oral atenolol
}

\author{
MILES K. TUTTON AND REDMOND J. H. SMITH \\ From Moorfields Eye Hospital, City Road, London EC1V 2PD
}

SUMMARY Oral atenolol ( $25 \mathrm{mg}$ twice daily and $50 \mathrm{mg}$ and $100 \mathrm{mg}$ once daily) and placebo were tested as additional therapy in a double-masked, randomised, cross-over study. Twenty-four patients (16 with chronic simple glaucoma and 6 with ocular hypertension) participated who had an intraocular pressure (IOP) higher than $21 \mathrm{mmHg}$. The mean fall of intraocular pressure varied between $28 \%$ and $36 \%$ and was observed 2 to 6 hours after administration. After 2 weeks of treatment there was still a small fall in intraocular pressure (13\%) after 12 hours (for the $25 \mathrm{mg}$ dose) and 24 hours (for the $50 \mathrm{mg}$ and $100 \mathrm{mg}$ dose), but this was not significant $(\mathrm{p}<0.5)$. There was a fall in blood pressure and reduced pulse rate which persisted for at least 30 hours. Some patients complained of tiredness during treatment periods. Oral atenolol may be useful additional therapy for glaucoma.

It is now well established that many drugs which block beta-adrenoreceptors also cause a fall in intraocular pressure (IOP). ${ }^{12}$ Atenolol (Tenormin) is a cardioselective beta- 1 blocker with a significantly lesser effect on airways resistance than a nonselective beta blocker. ${ }^{3}$ At present it is widely used to treat hypertension and has been shown to have an action both orally ${ }^{45}$ and topically ${ }^{68}$ on the eye, causing a large and rapid fall of intraocular pressure. This fall occurs within 2 hours of an oral dose, and its effect is known to continue for at least 10 hours. In addition longacting oral preparations of atenolol are thought to sustain a fall of the intraocular pressure for up to 24 hours. ${ }^{9}$

The aim of this study was to investigate, firstly, the use of atenolol as an addition to existing antiglaucoma medication in patients with either chronic simple glaucoma or ocular hypertension; secondly, to evaluate any dose-dependent intraocular pressurereducing ability with 3 dose strengths of oral atenolol, $25 \mathrm{mg}$ tablets twice daily in a soluble form, and $50 \mathrm{mg}$ and $100 \mathrm{mg}$ as once daily tablets in a long-acting form; and, finally, to ascertain whether the above doses could maintain a lower intraocular pressure after 12 hours for the soluble form and after 24 hours for the long-acting form.

Correspondence to Mr M. K. Tutton, Southampton Eye Hospital, Wilton Avenue, Southampton SO9 4XW.

\section{Patients and methods}

PATIENTS

Twenty-four patients (14 men and 10 women, mean age 72 years, range $55-85$ years) were selected randomly from patients attending the glaucoma clinic at the City Road branch of Moorfields Eye Hospital. Sixteen patients had chronic simple glaucoma (CSG) and 6 had ocular hypertension; all except one patient were receiving some antiglaucoma medication (Table 1). Patients were then screened and excluded if they had had any ocular surgery in the previous 3 months, if they were currently taking any other beta-blocker drug either ocularly or parenterally or had taken them in the previous 3 months, or if they had any history of asthma or cardiac failure. These criteria for screening were found adequate, and no physician's advice was required on individual patients.

All the patients had been attending regularly for several years and were selected because their intraocular pressures were stable on their usual medication. However, one or more readings over 21 $\mathrm{mmHg}$ must have been recorded during the introductory phasing. Their informed consent was then obtained for the investigations. Two of the patients (one with chronic simple glaucoma and one with ocular hypertension) were withdrawn from the trial, one after the first dose as she developed an ear infection and could no longer attend the clinic 
Table 1 Number of patients receiving other medication

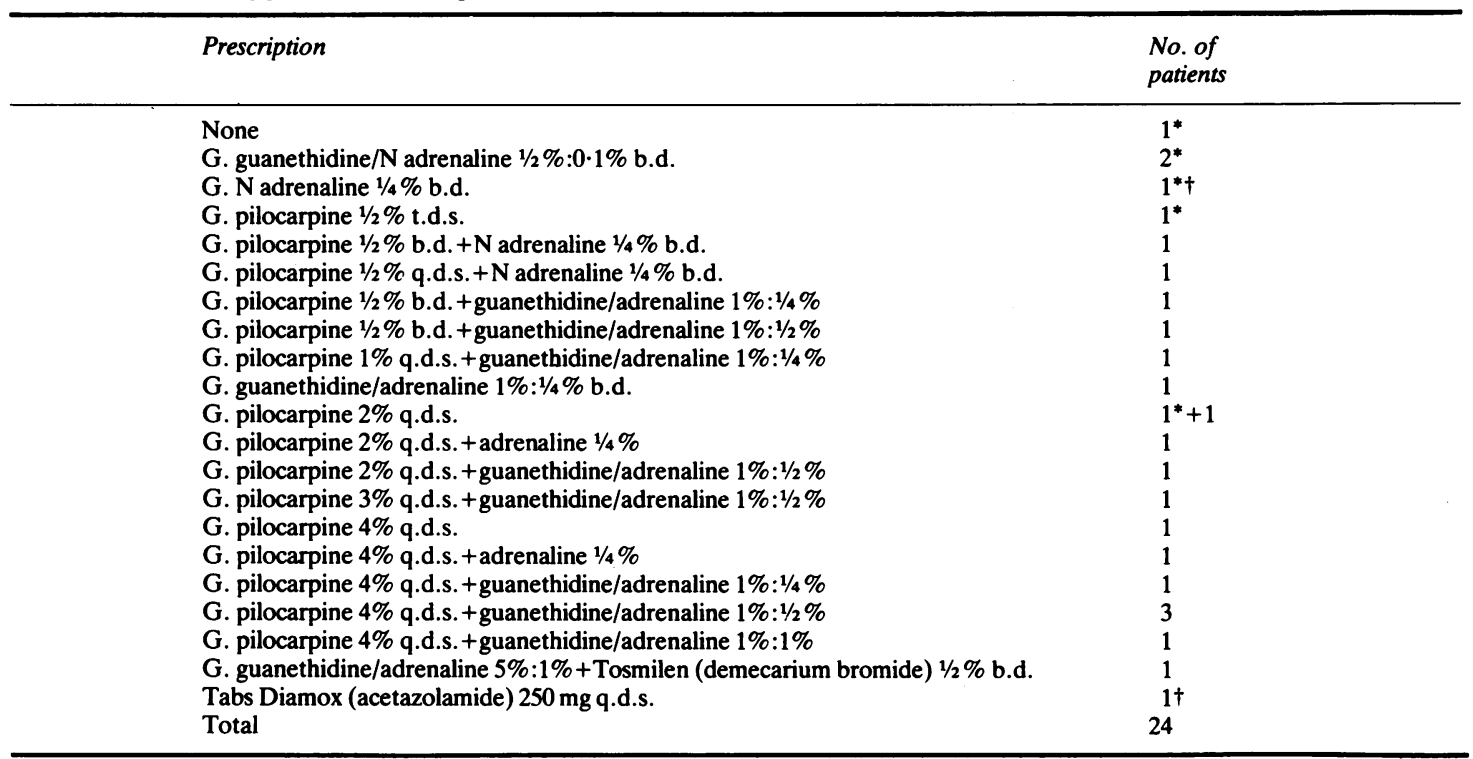

* Patients with ocular hypertension.

†Patients excluded (see text).

$\mathbf{G}=$ guttae. $\mathbf{N}=$ neutral.

regularly, and the second because his pressures were found during the phasing of the trial to be out of control and he required urgent surgery. Thus 22 patients completed the whole trial.

\section{MEASUREMENTS}

The 22 patients were phased over 8 visits. The first 2 visits were for baseline readings and the last 6 visits at 2-weekly intervals. During this period their usual medication was continued unaltered.

At each visit the following procedure was followed. On arrival the distance visual acuity was measured on a Snellen chart, both corneae were inspected, the standing blood pressure and radial pulse were recorded after standing for 2 minutes, and lastly the intraocular pressures were measured by a slit-lamp mounted, Goldmann applanation tonometer, the right eye before the left eye. All the blood pressures were recorded with a random-zero sphygmomanometer.

The patients were sorted into 2 batches of 11 patients and the initial starting times varied over 2 hours from approximately 08.45 to $10.45 \mathrm{a} . \mathrm{m}$. The same starting time for each patient was maintained throughout the study, and the 2-hourly intervals were rigidly maintained between measurements.

\section{DESIGN}

The first 2 days' measurements were treated as baseline readings and familiarised the patients with the testing procedure. Each patient received all 3 doses of atenolol for 2-weekly periods separated by 2 placebo periods of 2 weeks. The patients received tablets for the whole of the 'treatment' period, these being changed at each 2-weekly visit and the old bottles returned. The observer knew when there was a treatment period of 2 weeks but did not know what dose the patient received, the order having been randomly selected prior to the trial. Thus the trial was double-masked.

On each day 3 tablets were taken in the morning and one in the evening at $8 \mathrm{pm}$; placebo and active tablets looked identical.

If a patient's intraocular pressure was found on phasing to be out of control, the code was broken, but this occurred in only one patient, and his readings have been excluded from the analysis.

\section{Results}

A statistically significant decrease in mean intraocular pressure was found after 25,50 , and $100 \mathrm{mg}$ of atenolol on the first day (Table 2). The mean maximum fall $(7 \cdot 1,7 \cdot 3$, and $6 \cdot 2 \mathrm{mmHg}$ for 25,50 , and $100 \mathrm{mg}$ respectively) was recorded 4 hours after administration. After 12 hours (in the case of the 25 mg dose) or 24 hours (in the case of the $50 \mathrm{mg}$ and 100 $\mathrm{mg}$ doses) there was still a small fall below control values, though this was not significant $(p<0 \cdot 5)$.

There was no significant difference between the 
Table 2 Time course of fall of mean intraocular pressure in $\mathrm{mmHg} \pm S E M$, compared with control period during 14-day treatment with $25 \mathrm{mg}$ b.d., $50 \mathrm{mg}$, and $100 \mathrm{mg}$ atenolol daily

\begin{tabular}{|c|c|c|c|c|c|c|c|}
\hline & 2 hours & 4 hours & 6 hours & 12 hours & 14 hours & 16 hours & 18 hours \\
\hline \multirow[t]{2}{*}{25 mg b.d. } & $\begin{array}{c}-4.4 \\
\pm 0.76 \\
p<0.01\end{array}$ & $\begin{array}{c}-7.1 \\
\pm 0.81 \\
p<0.001\end{array}$ & $\begin{array}{c}-5.4 \\
\pm 0.84 \\
p<0.001\end{array}$ & $\begin{array}{c}-2.6 \\
\pm 1.01 \\
p<0.1\end{array}$ & $\begin{aligned} & -1.8 \\
& \pm 1.15 \\
p & <0.5\end{aligned}$ & $\begin{array}{c}-3.5 \\
\pm 1.15 \\
p<0.05\end{array}$ & $\begin{aligned} & -1.4 \\
& \pm 1.38 \\
p & <0.5\end{aligned}$ \\
\hline & & & & 24 hours & 26 hours & 28 hoürs & 30 hours \\
\hline 50 mg o.d. & $\begin{array}{c}-6.0 \\
\pm 0.8 \\
p<0.001\end{array}$ & $\begin{array}{c}-7.3 \\
\pm 0.75 \\
p<0.001\end{array}$ & $\begin{array}{c}-6.1 \\
\pm 0.81 \\
p<0.001\end{array}$ & $\begin{array}{c}-1.4 \\
\pm 0.81 \\
p<0.5\end{array}$ & $\begin{array}{c}-1 \cdot 1 \\
\pm 1 \cdot 25 \\
p<0.5\end{array}$ & $\begin{aligned} & -2 \cdot 5 \\
& \pm 1 \cdot 15 \\
p & <0 \cdot 1\end{aligned}$ & $\begin{array}{c}-1.2 \\
\pm 1.45 \\
p<0.5\end{array}$ \\
\hline 100 mg o.d. & $\begin{array}{c}-5.1 \\
\pm 0.71 \\
p<0.001\end{array}$ & $\begin{array}{c}-6.2 \\
\pm 0.69 \\
p<0.001\end{array}$ & $\begin{array}{c}-4.8 \\
\pm 0.81 \\
p<0.001\end{array}$ & $\begin{aligned} & -1.5 \\
\pm 0.71 & \\
p & <0.5\end{aligned}$ & $\begin{array}{l}-0.4 \\
\pm 0.79 \\
N S\end{array}$ & $\begin{array}{c}-3.2 \\
\pm 0.73 \\
p<0.5\end{array}$ & $\begin{array}{l}-0.5 \\
\pm 1.03 \\
N S\end{array}$ \\
\hline
\end{tabular}

NS= not significant.

mean values from both eyes either during the baseline readings or during treatment. The results have therefore been given as the average mean for both eyes. In addition, patients with either ocular hypertension or chronic simple glaucoma behaved similarly in this study and their results have been treated together.

There was a highly significant fall in pulse rate in all groups and this fall was maintained at the $\mathbf{3 0}$ hour reading. The systolic and diastolic blood pressure also showed a significant fall but the diastolic fall was slightly more marked. These falls were also persistent up to the 30 -hour reading.

\section{Discussion}

In this study oral atenolol was found to have a considerable hypotensive effect, particularly over the first 6 hours. However, after 24 hours the intraocular pressures were slightly reduced, but this was not found to be significant, although the fall in blood pressure and reduced pulse rate was maintained until at least 30 hours in this study. Stenkula and Wettrell ${ }^{9}$ found a larger fall in intraocular pressure throughout their study, although their study was on patients without their usual medication. Because this study showed a poor response at 24 hours, we concluded that one tablet a day (for example, $50 \mathrm{mg}$ atenolol) will not maintain a fall of intraocular pressure until the next tablet. Thus an oral dose of $50 \mathrm{mg}$ bd would give satisfactory control by providing a sustained fall of intraocular pressure between doses. This is opposite to the effect of twice daily atenolol in the treatment of hypertension, where a daily dose is sufficient. ${ }^{10}$

However, it was interesting that 3 patients mentioned that they had less ache in their eyes when they awoke in the morning and before they took a further atenolol tablet. This was distinctly different from their usual feelings when taking their usual antiglaucomatous drops. This awareness may indicate that there is less of a swing of intraocular pressure while the patient is on oral atenolol, and it merits further study.

Oral atenolol was well tolerated (Table 3 ), though 2 patients, both men (aged 65 years and 67 years),

Table 3 Number of patients with side effects

\begin{tabular}{ll}
\hline Side effects & No. (\%) \\
\hline Tiredness, attributable to treatment & $4(16)$ \\
Tiredness, not attributable to treatment & 1 \\
Less ache in the morning & $3(13)$ \\
Occasional dizziness & $6(27)$ \\
Palpitation-one occasion only & 1 \\
Ankle swelling-one occasion only & 1 \\
Loose motion-one occasion only & 1 \\
\hline
\end{tabular}

would not have liked to continue the treatment on account of the tiredness. However, the incidence of tiredness/fatigue is considerably higher than the $4 \%$ found in other studies ${ }^{11}$ and may be due to other factors-for example, the low numbers of patients in our study. Patients reported occasional episodes of dizziness. This is a recognised side effect of betablockers due to haemodynamic influence. Palpitations, ankle swelling, and loose motion occurred occasionally, but these are doubtful side effects, though they have been reported in other trials of beta-blockers.

We are grateful to ICI (Pharmaceuticals) Ltd for supplies of atenolol (Tenormin), for placebos, and for a grant for expenses, and to $\mathrm{Dr}$ Fitzsimons of ICI for helpful information and discussion. We also thank the staff of the glaucoma unit for their helpful administration. 


\section{References}

1 Mishima S. Ocular effects of beta-adrenergic agents. XII Jules Stein lecture. Surv Ophthalmol 1982; 27: 187-208.

2 Zimmermann TJ, Boger WP. The beta-adrenergic blocking agents and the treatment of glaucoma. Surv Ophthalmol 1979; 23: $347-422$.

3 Ellis ME, Sahay JN, Chatterjee SS, Cruickshank JM, Ellis SH. Cardio-selectivity of atenolol in asthmatic patients. Eur J Clin Pharmacol 1981;21: 173-6.

4 Elliot MJ, Cullen PM, Phillips CI. Ocular hypotensive effect of atenolol (Tenormin ICI): a new beta-adrenergic blocker. $\mathrm{Br} J$ Ophthalmol 1975; 59: 301 .

5 Wettrell K, Pandolfi M. Effect of oral administration of various beta-blocking agents on the intraocular pressure in healthy volunteers. Exp Eye Res 1975; 21: 452-6.
6 Phillips CI, Gore SM, MacDonald MJ, Cullen PM. Atenolol eye drops in glaucoma: a double-masked, controlled study. $\mathrm{Br} \mathrm{J}$ Ophthalmol 1977; 61: 349-353.

7 Wettrell K, Pandolfi M. Effect of topical atenolol on intraocular pressure. Br J Ophthalmol 1977; 61: 334-8.

8 Brenkman RF. Long term hypotensive effect of atenolol $4 \%$ eye drops. Br J Ophthalmol 1978; 62: 287-91.

9 Stenkula E, Wettrell K. A dose response study of oral atenolol administered once daily in patients with raised intraocular pressures. Albrecht von Graefes Arch Klin Ophthalmol 1982; 59: 375-7.

10 Castleden CM, Dathan JRE, George CF. A comparison of once and twice daily atenolol in hypertension. Postgrad Med J 1977; 53: 679-82.

11 Zacharias FJ, Cowan KJ, Cuthbertson PJR, et al. Atenolol in hypertension. A study of long term therapy. Postgrad Med J 1977; 53 (suppl 3): 102-10. 